\title{
Moisture sensitivity and dimensional stability of carbonated fibre-cement composites
}

Maan S. Hassan PhD

Assistant Professor in Sustainable Concrete Technology, Building and

Construction Engineering, University of Technology, Baghdad, Iraq

(corresponding author: 40018@uotechnology.edu.iq,

maan_s_h@yahoo.co.uk) (Orcid:0000-0002-5693-879X)

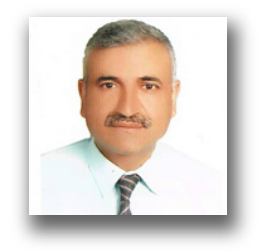

The aim of this work was to improve the long-term performance of fabricated eco-cement composites and demonstrate the value-added use of carbon dioxide $\left(\mathrm{CO}_{2}\right)$ in manufacturing sustainable products with better dimensional stability and moisture resistivity. Experiments were on pressed and non-pressed composites, fabricated with and without carbon dioxide curing. Dimensional stability comparisons were made between composites of date palm fibre and cement subjected to different moisture conditions, including air-dried, oven-dried and saturated conditions. Their flexural performances were then evaluated and compared with control specimens. The results revealed that the application of pressing and carbon dioxide curing as accelerating processing techniques have significant influences on the resultant products. The oven-dried composites exhibited poor flexural toughness behaviour compared with the air-dried or saturated specimens. Fibre growth in the transverse direction due to moisture conditions was observed to be efficient in strengthening the transition bonding areas with the matrix. In comparison with board length, the changes in board thickness and mass due to moisture effects were remarkable. This behaviour suggests that the final volume stability response of the composite is dominated by the orthotropic property due to the various constituents. Microstructural observations confirmed that carbon dioxide curing densified the matrix, leading to better dimensional stability of the composites, even after 25 wetting-drying cycles.

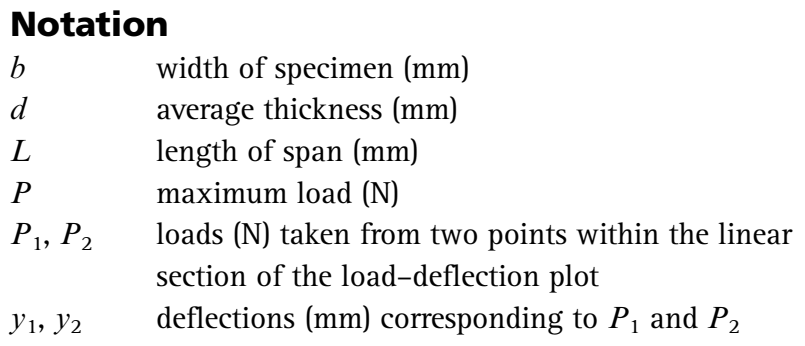

\section{Introduction}

A random distribution of short fibres in a cementitious matrix is considered a possible solution to overcome the brittle failure nature of the matrix (Hannant, 1978). Short fibres help to reduce crack propagation throughout the matrix by bridging opposite sides of cracks, thereby improving flexural toughness and crack resistance properties.

Date palm fibres (DPFs) are available in abundant quantities in Middle Eastern countries such as Iraq, Iran and Saudi Arabia (Nasser and Al-Mefarrej, 2011). These waste fibres are relatively strong, inexpensive, have a low energy demand and have proven to be effective in enhancing the flexural performance of cementitious composites, particularly when used with thin sheet sections (Ardanuy et al., 2015; Soroushian et al., 2013a, 2013b). However, compatibility problems between cellulose fibres and cement paste are a key concern in this research field. The alkaline pore water in the cement paste can react and attack the lignin and hemicellulose inside the middle sheets of cellulose DPFs. This attack causes considerable weakening in the tie bond between adjacent fibre cells and may lead to possible decomposition of the natural fibre constituents (Wei and Meyer, 2015).

Moisture movements allow the alkaline pore water to successfully reach the fibre cells and encourage an increasing decomposition process. Over time, such a process leads to embrittlement of the composite. Moreover, the cement hydration rate is reduced after the addition of cellulose fibres. Hemicellulose is well known to inhibit the setting of cement, and Sandermann and Kohler (1964) found that starches, sugars, tannins and certain phenols have an inhibitory effect on cement hydration reactions.

Repeated wetting and drying cycles also result in degradation and are thus considered aggressive conditions for 
natural-fibre-cement composites. The wetting phase of each cycle facilitates alkaline pore water reaching the fibre middle lamella, causing decomposition effects, while the drying phase removes decomposition products from the attacked fibre surface (Wei and Meyer, 2015). As a pozzolanic material, silica fume may help to partially resist this attack through reduction of the alkalinity of the cementitious matrix around the fibres (Mohr et al., 2007).

In developed countries, natural fibres used in cement composites are mostly produced by a chemical pulping method. Fibres produced by this method contain small amounts of lignin and thus can better resist alkaline attack due to the high $\mathrm{pH}$ value of the cementitious matrix. Developing countries in the Middle East produce large amounts of date palm waste every year. El-Juhany (2001) noted that approximately $35 \mathrm{~kg}$ of palm residues are obtained per tree every year. In the production of cellulosic fibres in developing countries, milling is preferred over pulping, and this method results in a higher lignin content. Therefore, unless pre-preparation procedures are implemented before the fabrication of cementitious composites, compatibility problems could arise (Mohr et al., 2005, 2006). The presence of moisture adds further complication to the situation as the core of the fibre cell will gradually be filled with cement hydration products (Bentur and Akers, 1989). However, advance preparation to remove lignin and other inhibitors can lead to improved flexural performance of cellulose fibre-cement composites, even in the presence of moisture.

\section{Accelerated carbon dioxide $\left(\mathrm{CO}_{2}\right)$ curing of cement composites}

Accelerated carbonation can partially contribute to a reduction of potential long-term degradation of cellulose-fibre-cement composites (Pizzol et al., 2014; Soroushian et al., 2012, 2013a, 2013b). It is generally accepted that carbon dioxide reacts with cement in two possible ways: $(a)$ reactions with unhydrated cement particles and $(b)$ reactions with cement hydration products. In both cases, the carbonation process appears to proceed in two steps. Firstly, carbonic acid $\left(\mathrm{H}_{2} \mathrm{CO}_{3}\right)$ is formed due to carbon dioxide dissolving in water. Subsequently, the carbonic acid reacts quickly with calcium silicates and, in a few minutes, produces calcium carbonate $\left(\mathrm{C}_{\mathrm{a}} \mathrm{CO}_{3}\right)$ and calcium silicate hydrate gel (C-S-H) (Soroushian et al., 2013a, 2013b). The governing reactions are as follows (Goodbrake et al., 1979; Young et al., 1974).

I. $\mathrm{C}_{3} \mathrm{~S}+(3-x) \mathrm{CO}_{2}+y \mathrm{H}_{2} \mathrm{O} \rightarrow \mathrm{C}_{x} \mathrm{SH}_{y}+(3-x) \mathrm{CaCO}_{3}$

\section{II. $\mathrm{C}_{2} \mathrm{~S}+(2-x) \mathrm{CO}_{2}+y \mathrm{H}_{2} \mathrm{O} \rightarrow \mathrm{C}_{x} \mathrm{SH}_{y}+(2-x) \mathrm{CaCO}_{3}$}

Furthermore, a reaction between calcium hydroxide $\left(\mathrm{Ca}(\mathrm{OH})_{2}\right)$ and the carbonic acid that has been formed could also occur throughout the carbon dioxide curing. This reaction can be expressed as follows.

$$
\text { III. } \mathrm{Ca}(\mathrm{OH})_{2}+\mathrm{H}_{2} \mathrm{CO}_{3} \rightarrow \mathrm{CaCO}_{3}+2 \mathrm{H}_{2} \mathrm{O}
$$

Another benefit of carbon dioxide curing as an early-age accelerated hardening method (Goodbrake et al., 1979; Young et al., 1974) is an improvement in the durability performance of cement-based composites due to the consumption of calcium hydroxide (Rostami et al., 2011). Tolêdo Filho et al. (2000) found that sisal and coconut fibres are highly sensitive to the alkalinity of a cementitious matrix. They reported that when the fibres were immersed in a calcium hydroxide solution at $\mathrm{pH} 12$ for $300 \mathrm{~d}$, they lost their flexibility completely and could be pulled apart easily by just finger force. Soroushian et al. (2013a, 2013b) also noted that carbon dioxide curing yielded major enhancements in the stability measurements of fibre-cement boards. Carbonation of the cementitious matrix may thus help to enhance the durability and the stability of cement-based composites.

Other researchers have also investigated the effects of carbon dioxide curing on the chemical composition of cement paste, the matrix capillary porosity, permeability and other durability properties (Almeida et al., 2013; Tonoli et al., 2010). Accelerated carbonation has been identified as a possible strategy to improve the flexural performance and volumetric stabilisation and provide improved longevity and weathering resistance of cement-based composites (Soroushian et al., 2012; Tolêdo Filho et al., 2003).

Moreover, accelerated carbonation is a sustainable and environmentally beneficial technology as carbon dioxide is chemically reintegrated with cement hydration products. Accelerated curing can thus use carbon dioxide recovered from cement kiln flue gas and recycle it within the cement and concrete industry.

The main aim of the work reported in this paper was to evaluate and improve the long-term performance and moisture sensitivity of cellulose DPF-cement composites using the advantages of carbon dioxide curing. Test specimens were subjected to accelerated ageing studies in the laboratory to simulate actual exposure conditions in the field. The specimens were then evaluated following relevant ASTM standards and the results were compared with unaged specimens. The results of this study should help design teams, site engineers, contractors and clients to choose an appropriate manufacturing process of cementitious boards with enhanced final performance and reduced environmental impact. The utilisation of carbon dioxide in this application reduces greenhouse emissions and also improves the productivity of cementitious board manufacturing plants. 


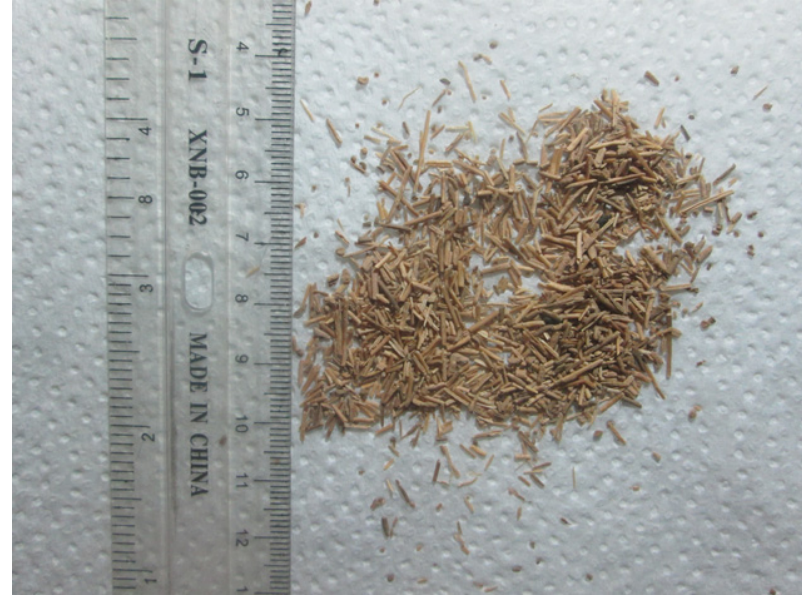

(a)

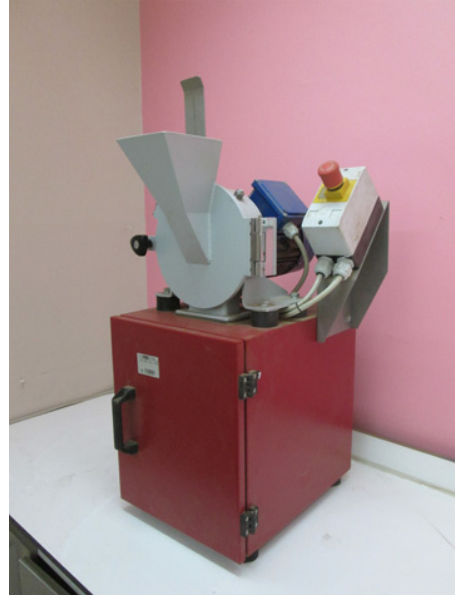

(b)

Figure 1. Appearance of hammer-milled DPFs (a) and machine used (b)

\section{Experimental programme}

Materials and manufacturing procedure

The cellulose fibres used in this study were DPFs (Figure 1(a)) with an average length of $5.75 \mathrm{~mm}$, thickness of $0.3 \mathrm{~mm}$ and dry density of $270 \mathrm{~kg} / \mathrm{m}^{3}$. The DPFs were pulled out trunks in the form of near cuboids (length 100-200 mm, width $50-100 \mathrm{~mm}$ and height $50-100 \mathrm{~mm})$. The DPFs were date palm (Phoenix dactylifera L.) residues collected from farming areas $20 \mathrm{~km}$ south of Baghdad, Iraq.

The trunk pieces were hammer-milled on a $3 \mathrm{~mm}$ mesh (Figure 1(b)), yielding the reinforcing elements (i.e. milled cellulose fibres) for use in cementitious boards at a $6 \%$ fibre mass fraction by weight of cement. Prior to addition to the cement mortar mixtures, the fibre pieces were subjected to pretreatments to mitigate the inhibitory effects of the fibres on cement hydration (Alawar et al., 2009). The fibres were soaked in hot water $\left(100^{\circ} \mathrm{C}\right)$ for $1 \mathrm{~h}$ and then cooled to room temperature. At the end of the treatment process, the fibres were ovendried at $60^{\circ} \mathrm{C}$ for $24 \mathrm{~h}$ and then sieved on a $600 \mu \mathrm{m}$ mesh to remove fine residues. Finally, to reduce moisture absorption, the dried fibres were kept in airtight polyethylene bags until they were used. The $6 \%$ fibre mass did not include any fibre moisture content due to the fibre treatment. The organic composition of the treated DPFs is presented in Table 1.

According to preliminary results, a matrix with mix proportions of $1: 0 \cdot 75: 0 \cdot 215$ (binder:sand:water/binder ratio) by weight was used. The binder consisted of $70 \%$ ordinary

Table 1. Composition of the treated DPFs

\begin{tabular}{|lccc|}
\hline Cellulose: $\%$ & Hemicellulose: $\%$ & Lignin: $\%$ & Ash: $\%$ \\
\hline 31.673 & 21.247 & 30.463 & 2.123 \\
\hline
\end{tabular}

Portland cement (OPC) conforming to ASTM C150 (ASTM, 2015a) and 30\% microsilica conforming to ASTM C1240-05 (ASTM, 2005). Table 2 shows the chemical composition and physical properties of the OPC and microsilica used in this study. The high ratio of microsilica used ensured an enhanced matrix structure, reduced porosity due to the filling ability of the microsilica and minimised composite degradation due to wet-dry cycling (Mohr et al., 2007). A polycarboxylate-based high-range water-reducing admixture conforming to ASTM C494 type F (ASTM, 2015b) was used to achieve the desired flow $(110 \pm 5 \%)$. The natural fine aggregate used in this study was obtained from Al Ekhaider quarry in Iraq and had a specific gravity, bulk density, sulphate content and absorption of $2 \cdot 65,1500 \mathrm{~kg} / \mathrm{m}^{3}, 0.07 \%$ and $1 \cdot 2 \%$, respectively. Its maximum size was $2.36 \mathrm{~mm}$ and the gradation was within the limits of ASTM C33 (ASTM, 2016). A flow table was used to measure the consistency of the mixture following ASTM C230 (ASTM, 2010).

The process used to manufacture cementitious thin sheets reinforced with cellulose fibre was similar to that used by

Table 2. Composition and properties of cement and microsilica

\begin{tabular}{lcc} 
& Cement & Microsilica \\
\hline Silicon dioxide $\left(\mathrm{SiO}_{2}\right): \%$ & 20.7 & 90.65 \\
Aluminium oxide $\left(\mathrm{Al}_{2} \mathrm{O}_{3}\right): \%$ & 4.61 & 0.02 \\
Ferric oxide $\left(\mathrm{Fe}_{2} \mathrm{O}_{3}\right): \%$ & 3.35 & 0.01 \\
Calcium oxide $(\mathrm{CaO}): \%$ & 61.89 & 1.22 \\
Magnesium oxide $(\mathrm{MgO}): \%$ & 3.05 & 0.01 \\
Sulfur trioxide $\left(\mathrm{SO}_{3}\right): \%$ & 2.4 & 0.24 \\
Lime saturation factor: \% & 0.87 & 0.48 \\
Loss on ignition: \% & 2.16 & 2.86 \\
Specific gravity & 3.1 & 2.4 \\
Specific surface area: $\mathrm{cm}^{2} / \mathrm{g}$ & 291 & 16000
\end{tabular}


Advances in Cement Research Volume 30 issue 9
Moisture sensitivity and dimensional stability of carbonated fibre-cement composites

Hassan
Alanbari et al. (2015) and Soroushian et al. (2012). Preparation of the fibre-reinforced cementitious thin sheet involved mixing all the constituents in a mortar mixer (following ASTM C305 (ASTM, 2011)) and then placing the blend in a plywood mould (300 mm length by $152.5 \mathrm{~mm}$ width) tied with steel plates. The targeted board thickness was $12 \mathrm{~mm}$.

Two types of boards were produced in this manner: pressed and non-pressed boards. For the pressed boards, the sheets were lightly pressed at $3.5 \mathrm{MPa}$ for $5 \mathrm{~min}$ (Mármol et al., 2013; Soroushian et al., 2013a, 2013b). Both types of board were then covered with nylon sheet to keep them in a moist condition. After $24 \mathrm{~h}$, the boards were demoulded and the specimens were ready for curing. Before carbon dioxide curing, young sheets were oven-dried for $30 \mathrm{~min}$ to lower the moisture content of the produced sheets to the point where carbon dioxide gases would be able to penetrate and react with the cementitious matrix (Soroushian et al., 2013a, 2013b).

Figure 2 shows the carbon dioxide curing system for the cement-bonded cellulose fibreboards. Different concentrations of carbon dioxide gas in air were produced by using two gas cylinders (one containing carbon dioxide and the other air). Each cylinder was connected to a flow meter, which controlled the gas flow level and thus the carbon dioxide concentration. The carbonation system setup was thus able to apply any blend of carbon dioxide and fresh air to the cementitious sheet. Figure 3 shows typical specimens after casting and young boards installed inside the carbon dioxide curing chamber ready for carbonation. The carbon dioxide

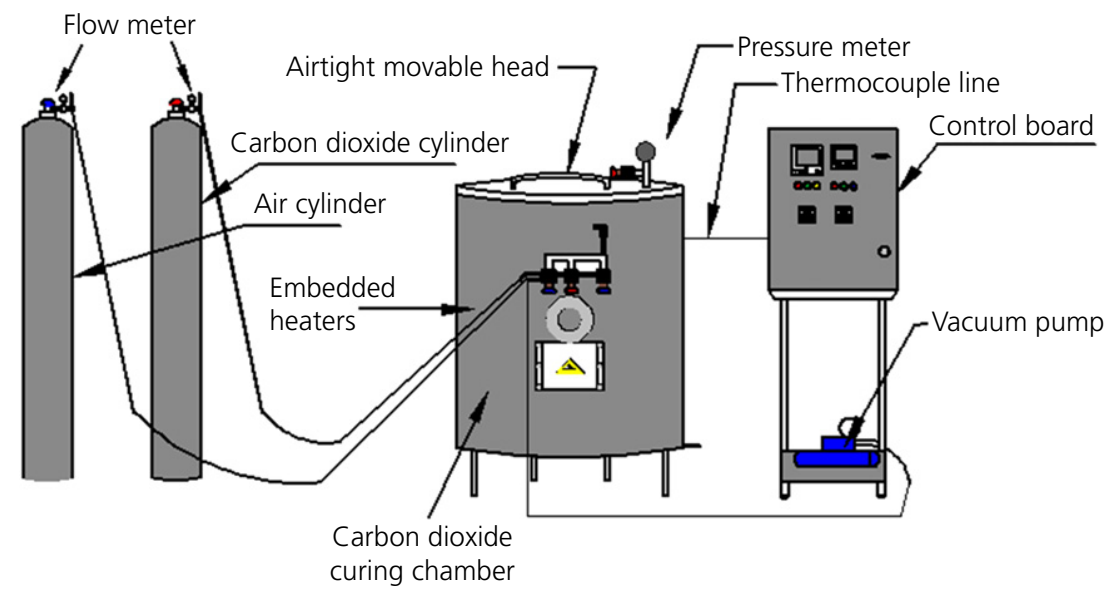

Figure 2. Carbon dioxide curing system

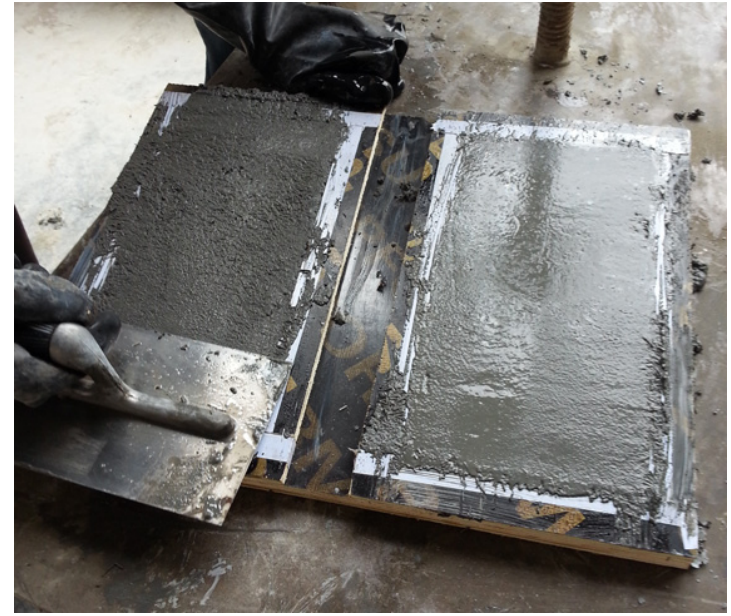

(a)

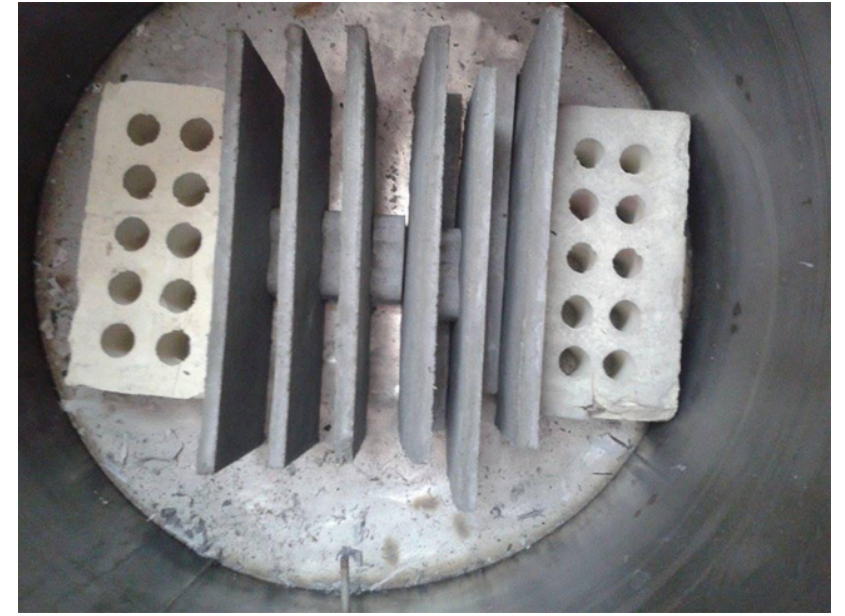

(b)

Figure 3. Typical specimen appearance after casting (a) and early age boards installed inside the carbon dioxide curing chamber ready for carbonation (b) 
concentration was kept constant at $50 \%$ in air inside the chamber and boards were cured for $2 \mathrm{~h}$. The specimens were then sealed wet in a plastic bag and held at room temperature until the age of $28 \mathrm{~d}$.

The moisture sensitivity and accelerated ageing effects on the flexural performance (strength, toughness and elasticity) of the composites were then evaluated.

\section{Test procedures}

Flexural tests were performed according to ASTM C1185-12 (ASTM, 2012). Three replicate flexural tests were conducted for each moisture condition. Flexural tests were performed on specimens with a clear span of $254 \mathrm{~mm}$. A displacement-controlled mode with a rate of $0.5 \mathrm{~mm} / \mathrm{min}$ was adopted in the flexure tests. The test data were recorded using a computercontrolled data acquisition system. The load-deflection curves were characterised by the modulus of rupture (MoR) and modulus of elasticity (MoE), according to Equations 1 and 2. The total area underneath the load-deflection curve represents flexural toughness. The flexural performance was evaluated under wet conditions. A deflectometer positioned in the middle span on the lower side of the board was used to record the deflection during the bending tests.

\section{1. $\mathrm{MoR}=3 P L / 2 b d^{2}$}

\section{2. $\mathrm{MoE}=\left(P_{2}-P_{1}\right) L^{3} / 4 b d^{3}\left(y_{2}-y_{1}\right)$}

In Equations 1 and 2, $P$ is the maximum load $(\mathrm{N}), L$ is the length of span (mm), $b$ is the width of specimen $(\mathrm{mm})$ and $d$ is the average thickness $(\mathrm{mm})$. Loads $P_{2}$ and $P_{1}(\mathrm{~N})$ were taken from two points within the linear section of the plot, with $y_{2}$ and $y_{1}$ being the deflections $(\mathrm{mm})$ corresponding to these selected loads.

Dimensional changes were measured in term of percentage changes in length, thickness and mass with respect to the original values according to the test procedures specified in BS 5669-4 (BSI, 1989) and ASTM C1185-12 (ASTM, 2012), which include increasing the relative humidity $(\mathrm{RH})$ from $30 \%$ to $90 \%$. Three replicates were tested and linear changes were calculated according to

3. Linear change $(\%)=\frac{L_{90 \% \mathrm{RH}}-L_{30 \% \mathrm{RH}}}{L_{30 \% \mathrm{RH}}} \times 100$

Changes in mass were calculated similarly.

\section{Moisture sensitivity}

Cementitious composites reinforced with cellulose fibres are sensitive to moisture. In this study, the effects of moisture on the produced composites were assessed using flexural tests. Three different moisture conditions were selected (Soroushian et al., 1994), air-dried (AD), oven-dried (OD) and saturated (SA), and flexural performance was evaluated and compared with unaged specimens (i.e. $28 \mathrm{~d}$ age). The moisture conditions, intended to simulate various environmental effects, are explained in Table 3. The temperature used for the AD and SA specimens $\left(23 \pm 3^{\circ} \mathrm{C}\right)$ represents normal conditions while temperature used for the OD specimens $\left(100 \pm 5^{\circ} \mathrm{C}\right)$ represents elevated temperature conditions. The increase from $23^{\circ} \mathrm{C}$ to $100^{\circ} \mathrm{C}$ was intended to raise the temperature within the matrix to the critical limit of $60-70^{\circ} \mathrm{C}$ (Taylor, 1997). Severe deleterious effects such as microcracks and shrinkage were expected to arise. Exposing cellulose-fibre-reinforced composites to rapid drying conditions may induce non-uniform drying shrinkage cracks (Aligizaki, 2006). Conversely, a higher moisture content can reduce the hydrogen bonding of the fibres to the matrix, leading to reduced MoE values and promoting radial fibre expansion (Soroushian et al., 1994). The final composite performance is thereby affected accordingly.

In this phase of the study, a full factorial experimental design of $3 \times 4 \times 3$ was implemented to investigate moisture effects on the flexural performance of the carbonated composites.

\section{Accelerated ageing wetting-drying cycles}

Natural ageing conditions such as rain, heat or solar radiation can cause thermal and mechanical internal stresses. The accelerated wetting-drying cycles conducted in this study were intended to partially simulate such natural weathering effects and to investigate the degradation of the cellulose fibre-cement composites due to alkaline attack. Repeated dissolving and reprecipitation of hydration products towards the cellulose fibre cells through their interfaces is another possible cause of degradation, which should also be investigated.

Wetting-drying tests were conducted following ASTM C118512 (ASTM, 2012). The procedure involved a cycle of $2 \mathrm{~h}$ and $55 \mathrm{~min}$ of water spraying at $30^{\circ} \mathrm{C}$, followed by another $2 \mathrm{~h}$ and $55 \mathrm{~min}$ of heating at $60 \pm 5^{\circ} \mathrm{C}$, with an interval of $5 \mathrm{~min}$ between the cycles. Two replicate specimens were subjected to

Table 3. Description of moisture conditions

$\begin{array}{ll}\text { Condition } & \text { Method } \\ \text { AD } & \text { Specimens were placed in a controlled environment } \\ \text { of } 23 \pm 3^{\circ} \mathrm{C} \text { and } \mathrm{RH} \text { of } 50-55 \% \text { for } 4 \mathrm{~d} \text {. All faces } \\ \text { were exposed to similar conditions and adequately } \\ \text { ventilated } \\ \text { Specimens were fired in an oven at } 100 \pm 5^{\circ} \mathrm{C} \text { until } \\ \text { the difference between two consecutive weighings, } \\ \text { within } 2 \mathrm{~h} \text {, was } \leq 0 \cdot 1 \% \text { of the specimen weight } \\ \text { Specimens were immersed in water at a temperature } \\ \text { of } 23^{\circ} \mathrm{C} \text { for } 2 \mathrm{~d} \text { and tested in a wet condition } \\ \text { (i.e. immediately after removal from water) }\end{array}$


a total of 25 cycles of wetting-drying and then tested under flexure. The flexural test results of aged board specimens were evaluated and compared with unaged specimens.

\section{Test results and discussion}

\section{Flexural performance of specimens under different} moisture conditions

Moisture content significantly affected the flexural performance (i.e. MoR and MoE) of the DPF-cement composites, whether the boards were pressed or not. Typical flexural performance curves of the pressed and non-pressed composites are shown in Figures 4 and 5, respectively. The effects of moisture on MoR, flexural toughness and MoE of both pressed and non-pressed and conventionally cured and aged composites are shown in Figures 6-8, respectively.

In general, the various moisture conditions produced significant differences in the MoR and MoE. Increases in moisture content level from $\mathrm{AD}$ to $\mathrm{SA}$ conditions resulted in adverse effects on the MoR (Figure 6) and MoE (Figure 8), for both the conventionally cured and carbon-dioxide-cured DPFcement composites. Flexural toughness, however, was enhanced with an increase in moisture level from $\mathrm{OD}$ to $\mathrm{AD}$ conditions (Figure 7). No further significant enhancement was found by increasing moisture to SA conditions, indicating that a high moisture content is not essentially proportionally beneficial in terms of flexural toughness. Carbon dioxide curing proved to produce better flexural performance (i.e. MoR, MoE and flexural toughness) regardless of the other processing aspects used, probably due to the impact of carbon dioxide in improving the matrix and board quality (Soroushian et al., 2013a, 2013b).

The stress-deflection curves presented in Figures 4 and 5 also reveal that, of the various moisture conditions, oven drying had major negative effects on flexural toughness. The negative volume change effects of dry heat $(2 \mathrm{~d}$ in the oven at $100 \pm 5^{\circ} \mathrm{C}$ ) outweighed the positive cement hydration effects promoted by heating. Oven drying could thus be responsible (Soroushian et al., 1994) for this behaviour, and this is suggested to be an area for further study. In Iraq and many other countries in the Middle East, hot and dry conditions are common, with temperatures reaching $55^{\circ} \mathrm{C}$. The test results in this study clearly indicate that such extreme hot and dry conditions have significant effects on final performance and should be accounted for in the design process.

The stress-deflection responses of the OD specimens (Figures 4(b) and 5(b)) showed a stable linear behaviour up to peak stress and then a sharp, steep post-cracking response was observed. Compared with the AD and SA specimens, both the pressed and non-pressed OD specimens generally showed a sharp transition from linear elastic to post-crack softening. This could be partially attributed to the more severe shrinkage effects of oven drying on the post-cracking response, as cellulose fibres can restore their size due to fibre saturation in wet

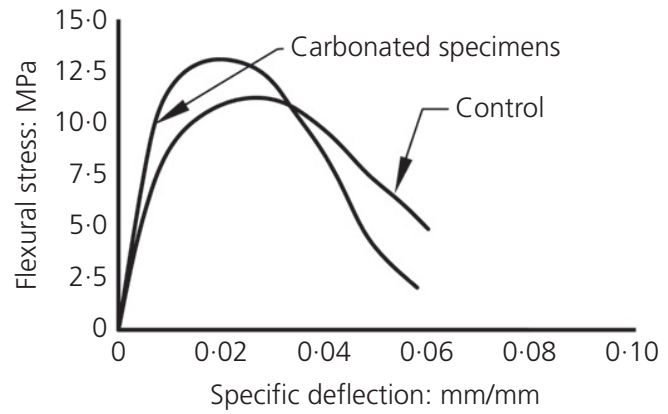

(a)

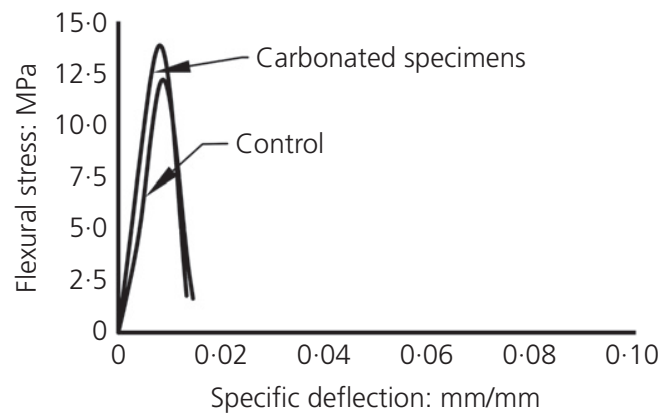

(b)

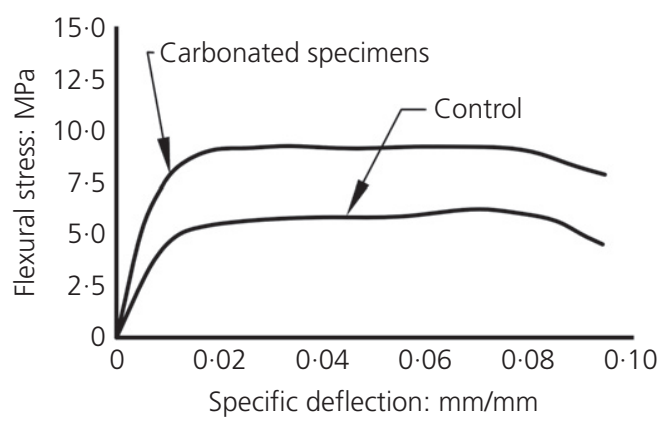

(c)

Figure 4. Typical curves of flexural stress against specific deflection for pressed composites reinforced with cellulose DPF at 28 d: (a) AD; (b) OD; (c) SA 


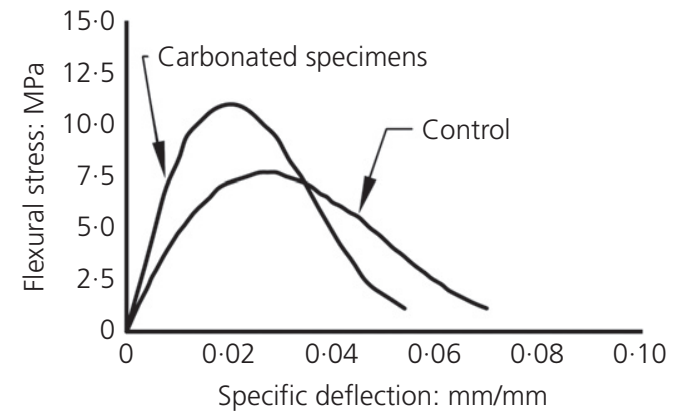

(a)

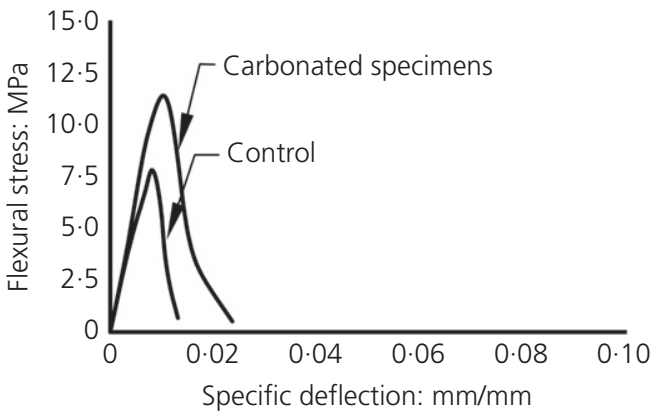

(b)

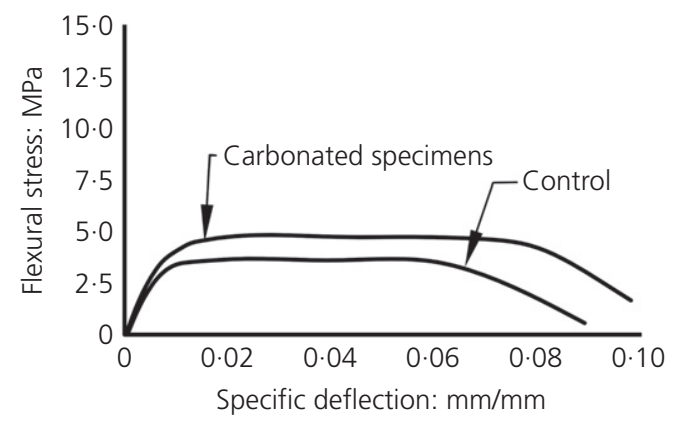

(c)

Figure 5. Typical curves of flexural stress against specific deflection for non-pressed composites reinforced with cellulose DPF at $28 \mathrm{~d}$ : (a) $A D$; (b) OD; (c) $S A$

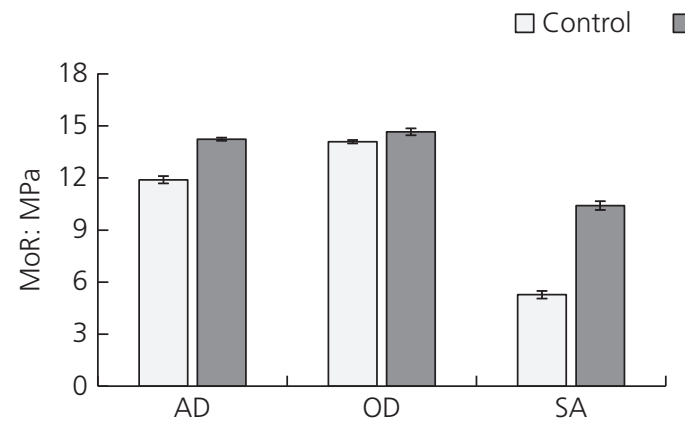

(a)
Cured in carbon dioxide

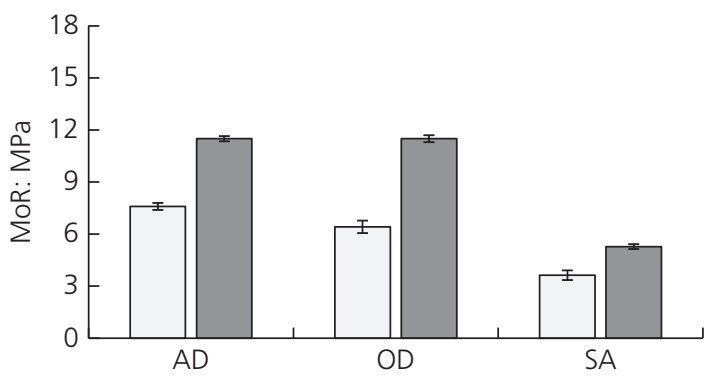

(b)

Figure 6. Effects of moisture condition on flexural strength (MoR): (a) pressed DPF boards; (b) non-pressed DPF boards. Error bars indicate standard deviation

testing conditions. Furthermore, the behaviour of these specimens, with no plasticity and limited toughness, clearly indicated that there was no fibre reinforcement effect. This could also be a consequence of possible fibre deterioration and fibre interface weakness at the high temperature $\left(100^{\circ} \mathrm{C}\right)$ of the OD condition. This weakness is permanent and cannot be compensated even after re-moistening with water. After the appearance of cracks (i.e. the post-cracking stage), the fibres become the main load carriers in the AD and SA specimens, leading to a gradual softening change in the post-cracking response (see Figures 4(a), 4(c) and 5(a), 5(c)). In the case of the OD composites, however, the role of the fibres was reversed and the fibres became a minor load carrier, probably due to the phenomena of fibre shrinkage, particularly in the transfer direction (Dinwoodie, 2002), which reduces the ability of the fibres to carry the transformed stresses. This issue will be discussed further later in the paper.

An analysis of variance (Anova) of the tested data is presented in Tables 4-7. The influence of moisture content, pressing and carbon dioxide curing on the flexural performance (MoR, MoE and flexural toughness) was confirmed at the 95\% level 


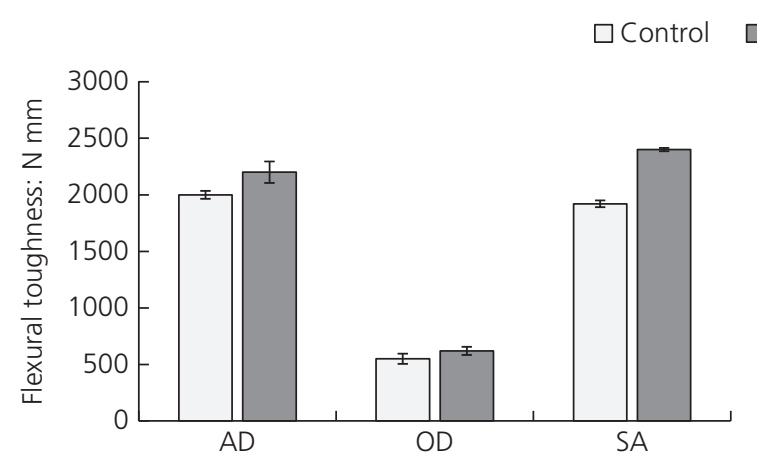

(a)

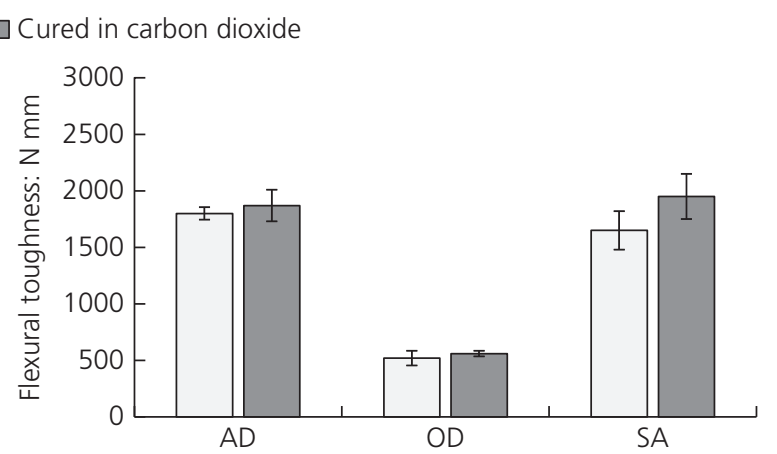

(b)

Figure 7. Effects of moisture condition on flexural toughness: (a) pressed DPF boards; (b) non-pressed DPF boards. Error bars indicate standard deviation

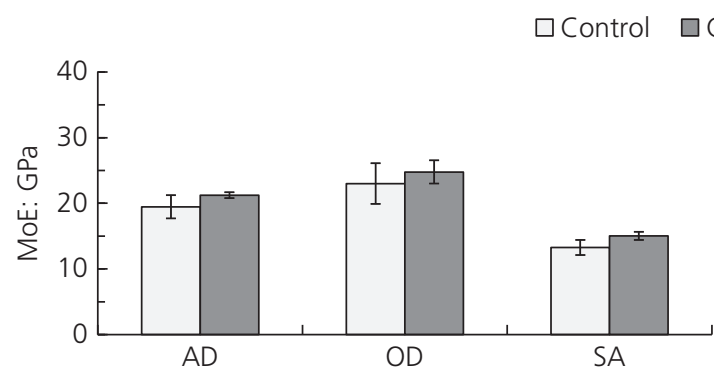

(a)

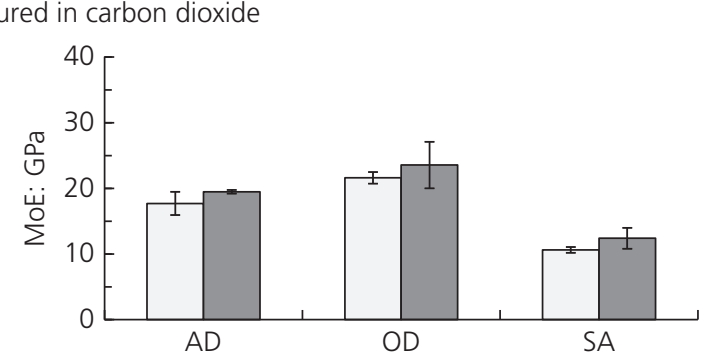

(b)

Figure 8. Effects of moisture condition on MoE: (a) pressed DPF boards; (b) non-pressed DPF boards. Error bars indicate standard deviation

Table 4. Anova of MoR test results of composites subjected to different moisture conditions prior to wet/dry cycling

\begin{tabular}{|c|c|c|c|c|c|c|c|c|c|c|c|c|}
\hline & \multicolumn{6}{|c|}{ Non-pressed } & \multicolumn{6}{|c|}{ Pressed } \\
\hline & \multicolumn{3}{|c|}{ Control } & \multicolumn{3}{|c|}{ Carbon dioxide curing } & \multicolumn{3}{|c|}{ Control } & \multicolumn{3}{|c|}{ Carbon dioxide curing } \\
\hline & $A D$ & OD & SA & $A D$ & OD & SA & $A D$ & OD & SA & $A D$ & OD & SA \\
\hline \multicolumn{13}{|c|}{ Control } \\
\hline$A D$ & $-{ }^{a}$ & - & $\star b$ & - & - & - & - & - & * & - & - & - \\
\hline OD & - & - & * & - & - & - & - & - & * & - & - & - \\
\hline SA & * & * & - & - & - & - & $\star$ & * & - & - & - & - \\
\hline \multicolumn{13}{|c|}{ Carbon dioxide curing } \\
\hline$A D$ & - & - & - & - & - & * & - & - & - & - & - & * \\
\hline $\mathrm{OD}$ & - & - & - & - & - & * & - & - & - & - & - & * \\
\hline SA & - & - & - & * & * & - & - & - & - & * & * & - \\
\hline
\end{tabular}

a - Statistically insignificant difference

b* Statistically significant difference at $95 \%$ level of confidence

of confidence (Table 7). Multiple comparisons between the $\mathrm{AD}$, OD and SA conditions of the Anova results confirmed the adverse effect of saturation on the MoR. This observation was consistent for both pressed and non-pressed boards (Table 4). Statistical analysis of the MoE and flexural toughness results confirmed the adverse effect of oven dying on the MoE and flexural toughness, at a 95\% level of confidence. In other words, flexural strength (MoR) was affected mainly by saturation, while the MoE and flexural toughness were affected mainly by oven drying (Tables 5 and 6). 
Table 5. Anova of MoE test results of composites subjected to different moisture conditions prior to wet/dry cycling

\begin{tabular}{|c|c|c|c|c|c|c|c|c|c|c|c|c|}
\hline & \multicolumn{6}{|c|}{ Non-pressed } & \multicolumn{6}{|c|}{ Pressed } \\
\hline & \multicolumn{3}{|c|}{ Control } & \multicolumn{3}{|c|}{ Carbon dioxide curing } & \multicolumn{3}{|c|}{ Control } & \multicolumn{3}{|c|}{ Carbon dioxide curing } \\
\hline & $A D$ & OD & SA & $A D$ & OD & SA & $A D$ & OD & SA & $A D$ & OD & SA \\
\hline \multicolumn{13}{|c|}{ Control } \\
\hline$A D$ & $-{ }^{a}$ & $\star b$ & - & - & - & - & - & * & * & - & - & - \\
\hline OD & * & - & * & - & - & - & * & - & - & - & - & - \\
\hline SA & - & * & - & - & - & - & * & - & - & - & - & - \\
\hline \multicolumn{13}{|c|}{ Carbon dioxide curing } \\
\hline$A D$ & - & - & - & - & * & - & - & - & - & - & * & * \\
\hline$O D$ & - & - & - & * & - & * & - & - & - & * & - & - \\
\hline SA & - & - & - & - & * & - & - & - & - & * & - & - \\
\hline
\end{tabular}

a - Statistically insignificant difference

$b_{*}$ Statistically significant difference at $95 \%$ level of confidence

Table 6. Anova of flexural toughness test results of composites subjected to different moisture conditions prior to wet/dry cycling

\begin{tabular}{|c|c|c|c|c|c|c|c|c|c|c|c|c|}
\hline & \multicolumn{6}{|c|}{ Non-pressed } & \multicolumn{6}{|c|}{ Pressed } \\
\hline & \multicolumn{3}{|c|}{ Control } & \multicolumn{3}{|c|}{ Carbon dioxide curing } & \multicolumn{3}{|c|}{ Control } & \multicolumn{3}{|c|}{ Carbon dioxide curing } \\
\hline & $A D$ & $O D$ & SA & $A D$ & OD & SA & $A D$ & OD & SA & $A D$ & OD & SA \\
\hline \multicolumn{13}{|c|}{ Control } \\
\hline$A D$ & $-{ }^{a}$ & $\star b$ & - & - & - & - & - & * & * & - & - & - \\
\hline$O D$ & * & - & * & - & - & - & * & - & * & - & - & - \\
\hline SA & - & * & - & - & - & - & * & * & - & - & - & - \\
\hline \multicolumn{13}{|c|}{ Carbon dioxide curing } \\
\hline$A D$ & - & - & - & - & * & - & - & - & - & - & * & - \\
\hline OD & - & - & - & * & - & * & - & - & - & * & - & * \\
\hline SA & - & - & - & - & * & - & - & - & - & - & * & - \\
\hline
\end{tabular}

a - Statistically insignificant difference

b* Statistically significant difference at $95 \%$ level of confidence

Table 7. Anova summary of flexural test results

\begin{tabular}{|c|c|c|c|c|c|c|}
\hline \multirow[b]{2}{*}{ Condition $^{a}$} & \multicolumn{2}{|c|}{ MoR } & \multicolumn{2}{|c|}{ Flexural toughness } & \multicolumn{2}{|c|}{ MoE } \\
\hline & F-ratio & $P$-value & F-ratio & $P$-value & F-ratio & $P$-value \\
\hline A & 3628 & $0.000^{b}$ & 54.5 & $0.000^{b}$ & 8.2 & $0.009^{b}$ \\
\hline B & 2072 & $0.000^{\mathrm{b}}$ & $36 \cdot 7$ & $0.000^{\mathrm{b}}$ & 7 & $0.014^{b}$ \\
\hline C & 2733 & $0.000^{\mathrm{b}}$ & 883 & $0.000^{\mathrm{b}}$ & 82 & $0.000^{\mathrm{b}}$ \\
\hline$A \times B$ & 40 & $0.000^{\mathrm{b}}$ & $3 \cdot 2$ & 0.085 & 0.002 & 0.96 \\
\hline$A \times C$ & 91 & $0.000^{b}$ & 9.6 & $0.001^{b}$ & 0.34 & 0.71 \\
\hline$B \times C$ & $5 \cdot 8$ & $0.009^{b}$ & $11 \cdot 4$ & $0.000^{\mathrm{b}}$ & 0.01 & $0 \cdot 9$ \\
\hline
\end{tabular}

${ }^{\mathrm{a}} \mathrm{A}$, pressing; $\mathrm{B}$ carbon dioxide curing, $\mathrm{C}$, moisture condition

${ }^{b}$ Statistically significant difference at $95 \%$ level of confidence

Figures 6-8 compare the flexural performance of pressed boards subjected to different moisture conditions to that of non-pressed boards. The flexural performance of the pressed composites was better than that of the non-pressed composites, at the $95 \%$ level of confidence. Pressing seems to have produced an enhanced matrix with consequent better board quality. Compared with the non-pressed boards, the pressed boards subjected to AD, OD and SA conditions had $40 \%$, $73 \%$ and $71 \%$ higher MoR, $14 \%, 8 \%$ and $19 \%$ higher flexural toughness, and $10 \%, 6 \%$ and $23 \%$ higher $\mathrm{MoE}$, respectively. 
Advances in Cement Research

Volume 30 issue 9
Moisture sensitivity and dimensional stability of carbonated fibre-cement composites

Hassan
The effect of pressing was thus more apparent in terms of the MoR. Flexural toughness is mainly dependent on the ability of the fibres to bridge cracks and whether the fibres break or pull out of the matrix. Hannant (1978) stated that improving the bond between fibres and the matrix (due to the pressing effect in this study) leads to improvements in the contact area and friction force at the interface and, ultimately, fibres break rather than pull out. This could explain the limited impact of pressing on flexural toughness in this work. On the other hand, MoE values are mainly affected by the composition and structure of the composite. The lower modulus of the fibre phase could explain the limited impact of pressing on the MoE.

\section{Fracture surface observations}

Inspection of the fracture surface provided some qualitative indications about the matrix microstructure of the cementitious composites. Typical scanning electron microscope photomicrographs of the composite boards taken in secondary electron mode for different curing procedures are presented in Figure 9. Figures 9(a) and 9(b) show non-carbonated and carbonated boards, respectively. The fracture surface of the carbondioxide-cured composites seemed to have a denser matrix and lower porosity, which led to the growth of overlapping compacted layers (labelled \#1 in Figure 9(b)) rather than separated clusters (labelled \#2 in Figure 9(a)).

Figure 9(b) shows that the combined effects of partial replacement of $30 \%$ of the cement by weight with silica fume and carbon dioxide curing produced a more homogenous matrix with smooth and homogeneous denser areas (labelled \#3) compared with the porous areas in the composite subjected to normal curing conditions (i.e. without carbonation) (labelled \#4 in Figure 9(a)). This matrix consisted mainly of C-S-H

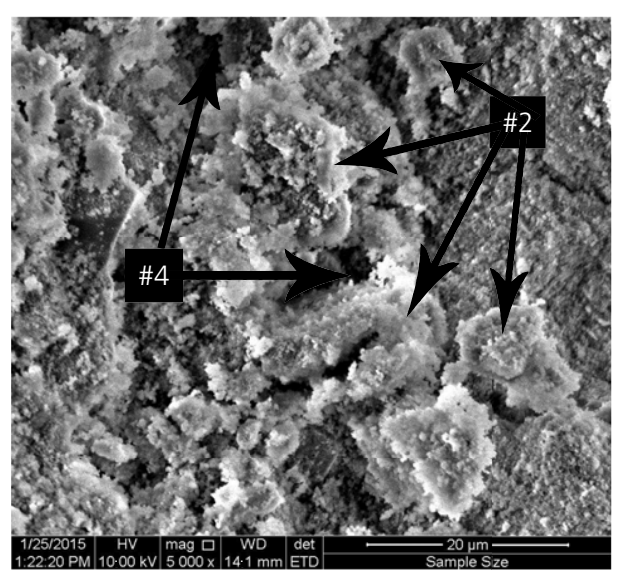

(a)

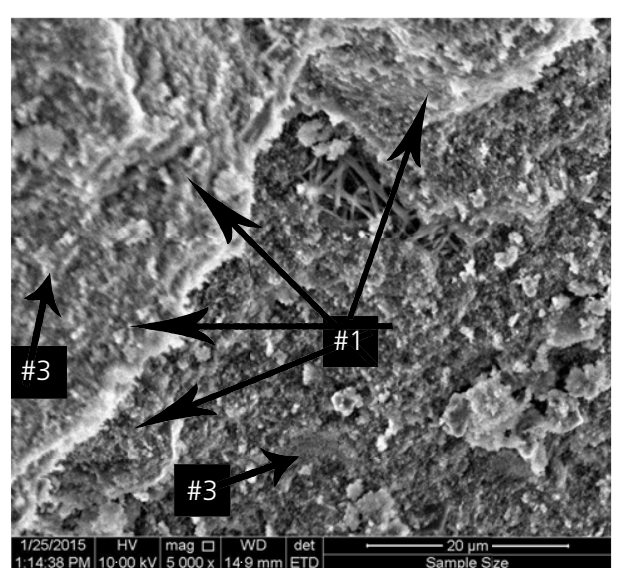

(b)

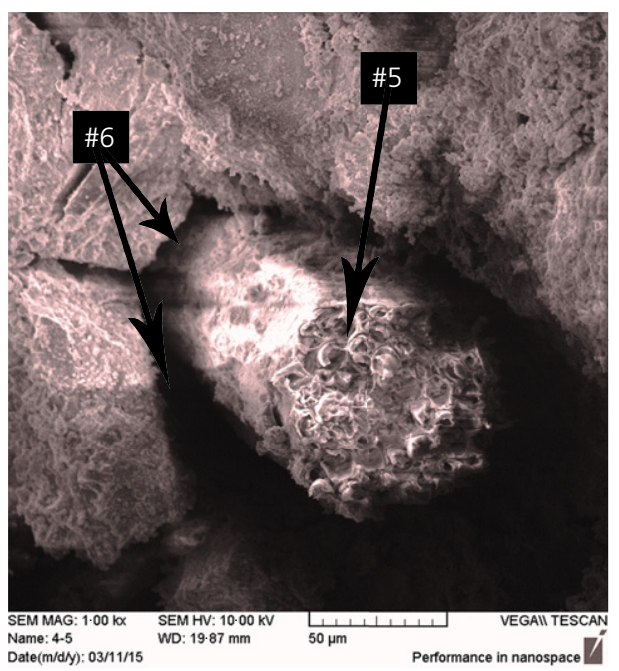

(c)

Figure 9. Fracture surface of fibre-reinforced cement composites: (a) non-carbonated specimens; (b) carbonated specimens; (c) carbonated specimens after wetting-drying. \#1, overlapping compacted area; \#2, separated clusters of hydration products; \#3, smooth and homogeneous denser area; \#4, porous area; \#5, fractured fibre; \#6, gap between fibre surface and matrix upon ageing 
and calcium carbonate products (Pizzol et al., 2014; Tonoli et al., 2016).

The calcium carbonate produced due to the carbon dioxide curing seemed to be responsible for enhancing the matrix-fibre interface through filling of the pore areas around the cellulose fibres (Hassan et al., 2016; Soroushian et al., 2013a, 2013b; Tonoli et al., 2016), leading to the formation of a rigid structure with lower moisture sensitivity and better dimensional stability. After accelerated ageing, progressive leaching of the hydration products weakened the fibre interface and a gap clearly appeared between the fibre surface and the surrounding matrix (\#5 and \#6 in Figure 9(c)).

\section{Moisture conditions and cyclic effects of wetting-drying on composite dimensional stability}

An increase in $\mathrm{RH}$ increase can lead to boards absorbing moisture and a corresponding swelling may occur. When the RH decreases, the boards could desorb moisture, causing a corresponding shrinkage (Fan et al., 1999; Soroushian et al., 2013a, 2013b). Marked change in mass and volume could then be expected. Cellulose fibres are much more susceptible to water than the surrounding cementitious matrix. Voids in the fibres comprise more than $50 \%$ of the total volume. When these voids are filled with moisture, the transverse radial fibre diameter increases, which can negatively affect the bonding of the fibre to the matrix (Page and Tydeman, 1963). The dimensional stability of specimens subjected to wetting-drying cycles and moisture effects was evaluated and compared with that of control specimens. Dimensional changes were measured in terms of percentage changes in length, thickness and mass according to Equation 3. The results presented in Figures 10-12 show percentage increases over the corresponding initial values. In comparison with the control (conventionally cured) specimens, all the carbon-dioxide-cured specimens exhibited better dimensional stability. In the case of moisture effects, the percentage reductions in mass, length and thickness of the carbon-dioxide-cured specimens relative to the non-carbonated specimens were $18 \%, 50 \%$ and $14.3 \%$, respectively. These enhancements were more pronounced in the pressed boards.

The negative impact of moisture conditions on the mass and thickness of the tested boards exceeded the effect on board length (Figures 10-12) partly because cellulose fibres and cement paste are normally unstable in water. Dimensional changes in wood fibres normally depend on the structure of the wood cell (i.e. softwood or hardwood) and the direction transverse change is more than ten times the longitudinal change (Dinwoodie, 2002) - whereas dimensional changes of cement pastes are considered to be isotropic in nature and a change of no more than $5 \%$ may be involved regardless of the direction (Fan et al., 1999). This phenomenon could explain

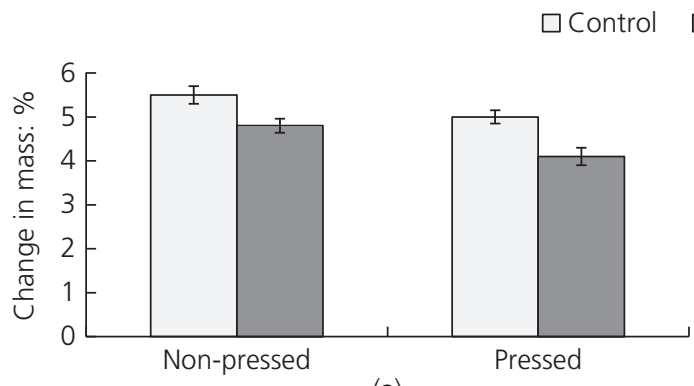

(a)

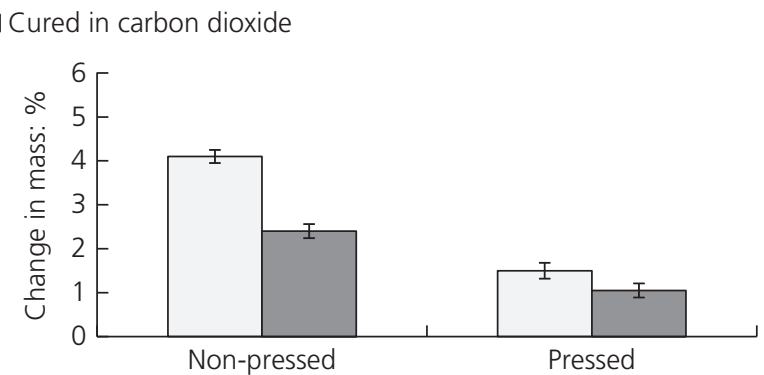

(b)

Figure 10. Change in mass due to (a) moisture effects and (b) repeated wetting-drying

$\square$ Control $\quad \square$ Cured in carbon dioxide

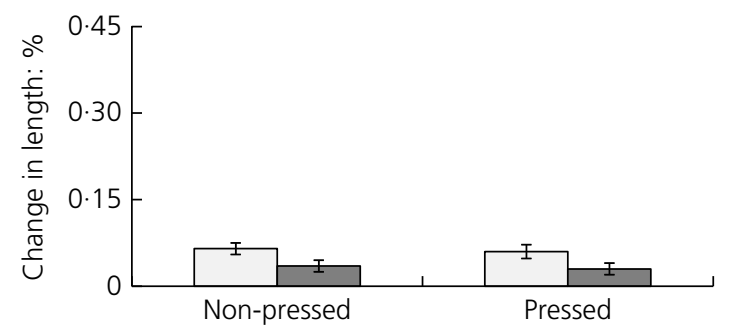

(a)

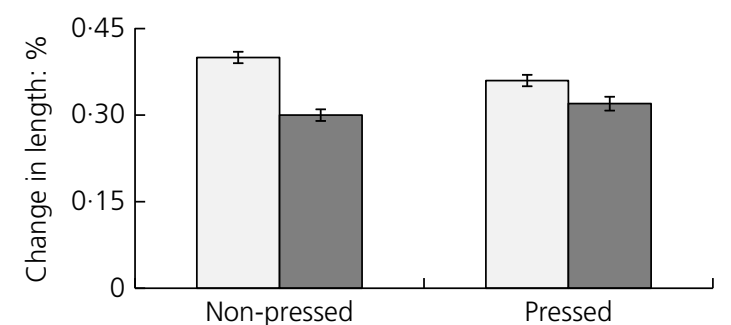

(b)

Figure 11. Change in length due to (a) moisture effects and (b) repeated wetting-drying 


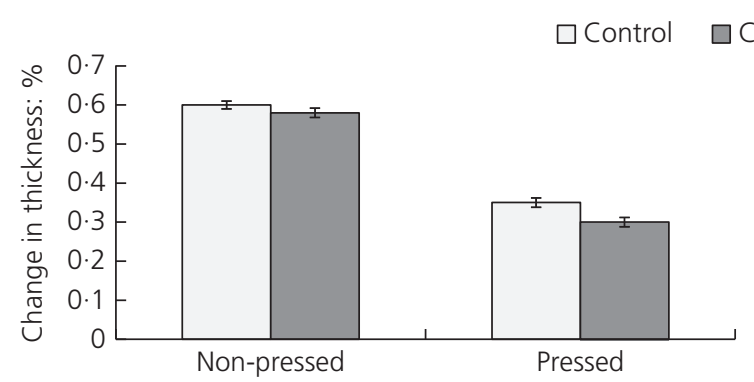

(a)

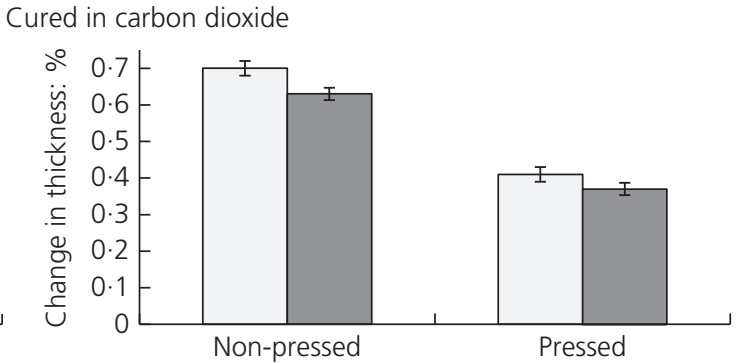

(b)

Figure 12. Change in thickness due to (a) moisture effects and (b) repeated wetting-drying

the significant impact of moisture conditions on the mass and thickness of the boards rather than their length.

After accelerated ageing, repeated wetting-drying cycles produced larger changes in both length and thickness (Figures 10(b), 11(b) and 12(b)), indicating lower dimensional stability of the resultant composites. The changes were more pronounced in the non-carbonated specimens, suggesting that carbon dioxide curing led to better dimensional stability. Compared with the wetted-dried, non-carbonated specimens, the wetted-dried carbonated specimens showed $41.4 \%, 25 \%$ and $39 \%$ reductions in mass, length and thickness, respectively. The change in length and mass due to wetting-drying cycles is dominated by the cementitious matrix, while the change in thickness is dominated by the cellulose fibres. The beneficial effect of carbon dioxide curing and the ability of the gas to penetrate the matrix pores meant that the non-pressed specimens outperformed the pressed specimens in terms of less change, as shown in Figures 10(b) and 11(b).

\section{Summary and conclusions}

Carbon-dioxide-cured cellulose-fibre-cement composites subjected to various moisture conditions and accelerated wettingdrying ageing cycles were examined in terms of flexural performance, dimensional changes and microstructural observations. The following conclusions were obtained from this study.

(a) The composites cured under carbon dioxide showed better resistance to moisture effects than the non-carbonated boards. This enhancement was consistent regardless of the other processing aspects used.

(b) Different types of moisture conditions were found to have different effects on flexural performance. The flexural strength was adversely affected by saturation conditions. The effect of air drying and oven drying on flexural strength were negligible. This behaviour was consistent for both the conventionally cured and carbon-dioxidecured cementitious composites. (c) The DPF composites subjected to oven drying exhibited poor flexural toughness behaviour compared with the composites subjected to air drying or saturation. This behaviour was consistent for both the conventionally cured and the carbon-dioxide-cured cementitious composites. Furthermore, with an increase in moisture, fibre growth in the transverse direction seemed to be efficient in strengthening the transition bonding areas with the surrounding matrix. Anova of the results, at the $95 \%$ level of confidence, confirmed the statistical significance of moisture on the ductility behaviour of the cellulose DPF-cement composites.

(d) Oven drying generally had adverse effects on the post-cracking response of the tested composites. While the fibres were the main load carriers in the specimens subjected to air drying and saturation, leading to a gradual softening change in post-cracking response, they played a minor role in the oven-dried composites, probably due to shrinkage of the wood fibres, possible fibre deterioration and weakening of the fibre interface.

(e) In comparison with the change in fibreboard length, the percentage increases in the thickness and mass of the boards due to moisture effects were notable. This behaviour suggests that the final volume stability response was dominated by orthotropic properties due to the various constituents of the composite. The structure of the wood fibre and internal stresses generated during these changes are other possible factors for this difference.

$(f)$ The changes in length and thickness of the fibreboards after repeated wetting-drying cycles were notable and associated with a mass increase. However, the aggravated effects were less pronounced in both pressed and carbonated composites compared with non-pressed and non-carbonated composites, respectively.

( $g$ ) The calcium carbonate produced due to carbon dioxide curing participated in filling the $\mathrm{C}-\mathrm{S}-\mathrm{H}$ inner porosity of the cement paste and decreasing 
liquid transportation during repeated wetting-drying cycles. The interface between the fibres and the matrix in the carbonated composites was also improved, leading to better dimensional stability of the composites, as indicated by the smaller changes in thickness, length and mass percentages compared with non-carbonated composites even after 25 wetting-drying cycles.

In summary, this work has demonstrated the beneficial effects of using carbon dioxide curing in combination with other processing aspects as a sustainable method to improve the moisture sensitivity and the dimensional stability of DPF-cement composites.

\section{Acknowledgements}

The author would like to thank the departments of Building and Construction Engineering and Materials Engineering of the University of Technology, Baghdad, Iraq, for extending their facilities for this research work

\section{REFERENCES}

Alanbari R, Hassan MS and Fakhri AH (2015) Manufacturing of sustainable cellulose date palm fiber reinforced cementitious boards in Iraq. Engineering and Technology Journal 33(7): 1680-1696.

Alawar A, Hamed AM and Al-Kaabi K (2009) Characterization of treated date palm tree fiber as composite reinforcement. Composites Part $B$ : Engineering 40(7): 601-606.

Aligizaki KK (2006) Pore Structure of Cement Based Materials: Testing, Interpretation and Requirements. Taylor \& Francis, New York, NY, USA.

Almeida AEFS, Tonoli GHD, Santos SF and Savastano Jr. H (2013) Improved durability of vegetable fiber reinforced cement composite subject to accelerated carbonation at early age. Cement \& Concrete Composites 42: 49-58, https://doi.org/10.1016/j.cemconcomp.2013. 05.001 .

Ardanuy M, Claramunt J and Toledo Filho RD (2015) Cellulosic fiber reinforced cement-based composites: a review of recent research. Construction and Building Materials 79: 115-128, https://doi.org/ 10.1016/j.conbuildmat.2015.01.035.

ASTM (2005) C1240-05: Standard specification for silica fume used in cementitious mixtures, ASTM International, West Conshohocken, PA, USA.

ASTM (2010) C230: Standard specification for flow table for use in tests of hydraulic cement 1. ASTM International, West Conshohocken, PA, USA.

ASTM (2011) C305: Standard practice for mechanical mixing of hydraulic cement pastes and mortars of plastic consistency. ASTM International, West Conshohocken, PA, USA.

ASTM (2012) C1185-12: Standard test methods for sampling and testing non-asbestos fiber-cement flat sheet, roofing and siding shingles, and clapboards. ASTM International, West Conshohocken, PA, USA.

ASTM (2015a) C150: standard specification for Portland cement. ASTM International, West Conshohocken, PA, USA.

ASTM (2015b) C494: Standard specification for chemical admixtures for concrete. ASTM International, West Conshohocken, PA, USA.
ASTM (2016) C33: Standard specification for concrete aggregates. ASTM International, West Conshohocken, PA, USA.

Bentur A and Akers SAS (1989) The microstructure and ageing of cellulose fibre reinforced cement composites cured in a normal environment. International Journal of Cement Composites and Lightweight Concrete 11(2): 99-109.

BSI (1989) BS 5669-4: Particleboard. BSI, London, UK.

Dinwoodie JM (2002) Timber: Its Nature and Behaviour, 2nd edn. E \& FN Spon, London, UK

El-Juhany LI (2001) Surveying of lignocellulosic agricultural residues in some major cities of Saudi Arabia. Research Bulletin 1: $50-53$

Fana MZ, Bonfielda PW, Dinwoodiea JM and Breeseb MC (1999) Dimensional instability of cement-bonded particleboard mechanisms of deformation of CBPB. Cement and Concrete Research 29(6): 923-932.

Goodbrake C, Young JF and Berger RL (1979) Reaction of betadicalcium silicate and tricalcium silicate with carbon dioxide and water vapor. Journal of the American Ceramic Society 62(3-4): $168-171$.

Hannant DJ (1978) Fibre Cements and Fibre Concretes. Wiley, New York, NY, USA.

Hassan MS, Salih SA and Ali IM (2016) Strength evaluation of $\mathrm{CO}_{2}$-cured cellulose date palm fiber reinforced cementitious boards. Engineering and Technology Journal 34(6): 1029-1046.

Mármol G, Santos SF and Savastano Jr. H et al. (2013) Mechanical and physical performance of low alkalinity cementitious composites reinforced with recycled cellulosic fibres pulp from cement kraft bags. Industrial Crops and Products 49: 422-427, https://doi.org/10. 1016/j.indcrop.2013.04.051.

Mohr BJ, Nanko H and Kurtis KE (2005) Durability of kraft pulp fibercement composites to wet/dry cycling. Cement \& Concrete Composites 27(4): 435-448.

Mohr BJ, Biernacki JJ and Kurtis KE (2006) Microstructural and chemical effects of wet/dry cycling on pulp fiber-cement composites. Cement and Concrete Research 36(7): 1240-1251

Mohr BJ, Biernacki JJ and Kurtis KE (2007) Supplementary cementitious materials for mitigating degradation of kraft pulp fiber-cement composites. Cement and Concrete Research 37(11) 1531-1543.

Nasser RA and Al-Mefarrej HA (2011) Midribs of date palm as a raw material for wood-cement composite industry in Saudi Arabia. World Applied Sciences Journal 15(12): 1651-1658.

Page DH and Tydeman PA (1963) Transverse swelling and shrinkage of softwood tracheids. Nature 199(4892): 471-472.

Pizzol VD, Mendes LM, Frezzatti L, Savastano H Jr. and Tonoli GHD (2014) Effect of accelerated carbonation on the microstructure and physical properties of hybrid fiber-cement composites. Minerals Engineering 59: 101-106, https://doi.org/10.1016/j.mineng.2013. 11.007.

Rostami V, Shao Y and Boyd AJ (2011) Durability of concrete pipes subjected to combined steam and carbonation curing. Construction and Building Materials 25(8): 3345-3355.

Sandermann W and Kohler R (1964) Studies on mineral bonded wood materials VI. A short test of the aptitude of woods for cement bonded materials. Holzforschung 18(1/2): 53-59.

Soroushian P, Shah Z, Won JP and Hsu JW (1994) Durability and moisture sensitivity of recycled wastepaper-fiber-cement composites. Cement \& Concrete Composites 16(2): 115-128.

Soroushian P, Won JP and Hassan M (2012) Durability characteristics of $\mathrm{CO}_{2}$-cured cellulose fiber reinforced cement composites. Construction and Building Materials 34: 44-53, https://doi.org/ 10.1016/j.conbuildmat.2012.02.016.

Soroushian P, Won JP and Hassan MS (2013a) Sustainable processing of cellulose fiber cement composites. ACI Materials Journal 110(3): 305-314. 
Advances in Cement Research

Volume 30 issue 9
Moisture sensitivity and dimensional stability of carbonated fibre-cement composites

Hassan
Soroushian P, Won JPP and Hassan M (2013b) Durability and microstructure analysis of $\mathrm{CO}_{2}$-cured cement-bonded wood particleboard. Cement \& Concrete Composites 41: 34-44, https:// doi.org/10.1016/j.cemconcomp.2013.04.014.

Taylor HFW (1997) Cement Chemistry, 2nd edn. Thomas Telford, London, UK.

Tolêdo Filho RD, Scrivener K, England GL and Ghavami K (2000) Durability of alkali-sensitive sisal and coconut fibres in cement mortar composites. Cement \& Concrete Composites 22(2): 127-143.

Tolêdo Filho RD, Ghavami K, England GL and Scrivener K (2003)

Development of vegetable fibre-mortar composites of improved durability. Cement \& Concrete Composites 25(2): 185-196.

Tonoli GHD, Santos SF, Joaquim AP and Savastano Jr H (2010) Effect of accelerated carbonation on cementitious roofing tiles reinforced with lignocellulosic fibre. Construction and Building Materials 24(2): 193-201.

Tonoli GHD, Pizzol VD, Urrea G et al. (2016) Rationalizing the impact of aging on fiber-matrix interface and stability of cement-based composites submitted to carbonation at early ages. Journal of Materials Science 51(17): 7929-7943.

Wei J and Meyer C (2015) Degradation mechanisms of natural fiber in the matrix of cement composites. Cement and Concrete Research 73: 1-16, https://doi.org/10.1016/j.cemconres. 2015.02.019.

Young JF, Berger RL and Breese J (1974) Accelerated curing of compacted calcium silicate mortars on exposure to $\mathrm{CO}_{2}$. Journal of the American Ceramic Society 57(9): 394-397.

\section{How can you contribute?}

To discuss this paper, please submit up to 500 words to the editor at journals@ice.org.uk. Your contribution will be forwarded to the author(s) for a reply and, if considered appropriate by the editorial board, it will be published as a discussion in a future issue of the journal. 